\title{
Differentiation and Cell Kinetics of Mammary Gland in Pubescent Virgin Rats Treated with Bromocriptine
}

\author{
Tokuko Sakaki \\ Department of Pathology, Kansai Medical University, \\ Moriguchi, Osaka 570, Japan \\ (Received for Publication March 10, 1988) \\ Key words : Mammary gland, Prolactin, BrdU, Bromocriptine
}

\begin{abstract}
Summary
Sprague-Dawley female rats were orally administered $10 \mathrm{mg} / \mathrm{kg}$ of Bromocriptine (CB) daily between 31 to 51 days of age. In meta- and di-estrus rats with regular sex cycles, serum prolactin (PRL) was elevated for 3 days and peaked at 2 days $(96.6 \pm 9.82 \mathrm{ng} / \mathrm{ml}$ ) after the termination of subchronic treatment, compared with those $(2.1 \pm 0.29 \mathrm{ng} / \mathrm{ml})$ at the termination. Untreated, ovariectomized, and ovariectomized and $\mathrm{CB}$-treated rats were used as controls, and mammary gland development was observed in relation to the serum PRL fluctuation in such regularly sex-cycling meta- and di-estrus rats. Compared with untreated controls, the mammary gland exhibited significantly predominant terminal ducts (TD) with an accompanying decrease in alveolar buds (AB) in nearly normal-sized parenchyma at the termination of subchronic treatment with CB. It also exhibited a marked predominance of lobules (Lob) and AB with fewer TD in larger parenchyma 3 and 6 days after the termination. Immunohistochemically, there were fewer bromodeobxyuridine ( $\mathrm{BrdU})$-labeled glandular cells in terminal end buds (TEB) and TD at termination, and more in ducts and $A B 3$ days after termnation, compared with untreated controls. Therefore, the development of the mammary glands is retarded in rats with low serum PRL levels, and a rebound increase in PRL levels accelerated the development.
\end{abstract}

\section{Introduction}

PRL, growth hormone, folliculoids, luteoids, corticoids, epidermal growth factor, insulin, etc. have been proposed as mammotrophic substances in vitro ${ }^{1)}$. In particular, PRL was required for ductal and alveolar growth of mammary gland in vivo but its action was often hampered by the fact that, in vivo, a hormone is dependent upon rather than independent of other hormones. Forsyth et al. ${ }^{2)}$ have reported the inhibition of mammary gland development and milk yield in goats by chronic suppression of PRL secretion with CB although serum 
$S-16$

levels of ovarian hormones were unaffected by the long-term treatment. Recently, we observed a regular sex cycle in pubescent virgin rats treated with a non-toxic but effective dose of $C B$, even during withdrawn periods revealing a rebound increase of serum PRL. In this paper, a quantitative estimation of cell kinetics related to the differentiation of the mammary gland is described in rats with serum PRL fluctuations using immunohistochemical techniques.

\section{Materials and Methods}

\section{1) Animal Protocols}

Sprague-Dawley female rats 21 days old were purchased from Japan Clea Lab., Ltd., housed in an air-conditioned and artificially illuminated room (14 hours of light ; $6 \mathrm{am}-8 \mathrm{pm}$ ), and given freely a commercial diet and tap water. They were divided into 6 experimental groups as indicated in Table 1. Ten $\mathrm{mg} / \mathrm{kg}$ of Bromocriptine (Parlodel of Sandoz Ltd., ) suspended in $0.5 \mathrm{ml}$ of $2.5 \%$ arabian gum solution, was orally given every morning using a gastric tube between the ages of 31 to 51 days. Ovariectomy was done bilaterally at the age of 28 days. Early each morning, all of the rats were weighed and vaginal smears were taken after vaginal openings had developed (around 40 days of age). To evaluate serum PRL levls, peripheral blood samples were collected from the tail veins only meta- and di-estrous rats in the morning between the age of 51-57 days. Blood sampling was performed as quickly and as gently as possible without the use of anesthesia. Sampling was not repeated in any animal. To enhance the reliability of the data, a total of 91 blood samples were collected in a similar manner by the co-authors and analyzed. All of the serum was frozen and kept at $-20^{\circ} \mathrm{C}$ until measurement using a radioimmunoassay technique, which could be kindly performed by Dr. Y. Kato, Shimane Medical University. Thereafter, all of the examined rats were injected intraperitoneally wirh $200 \mathrm{mg} / \mathrm{kg}$ of $\mathrm{BrdU} 2 \mathrm{hr}$ prior to sacrifice ${ }^{3)}$. Only meta- and di-estrous CB-treated rats (Groups 2, 3, and 4, ) were sacrificed by decapitation at 51, 54, and 57

Table 1 Experimental Groups

\begin{tabular}{ccll}
\hline Group & $\begin{array}{l}\text { Number } \\
\text { of rats }\end{array}$ & Experimental design & $\begin{array}{c}\text { Age of sacrifice** } \\
\text { (days) }\end{array}$ \\
\hline 1 & 5 & Untreated & $51,54,57$ \\
2 & 5 & Bromocriptine* & 51 "Day 0" \\
3 & 5 & Bromocriptine* & 54 "Day 3" \\
4 & 6 & Bromocriptine* & 57 "Day 6" \\
5 & 7 & Ovariectomy & 51 \\
6 & 7 & Ovx + Bromocriptine* & 51 "Day 0" \\
\hline
\end{tabular}

* Daily intubation of Bromocriptine, $10 \mathrm{mg} / \mathrm{kg}$, between ages of 31 to 51 days. Ovariectomy was performed at the age of 28 days.

** Only meta- or di- estrous rats were sacrificed.

"Day" means day after the last intubation of Bromocriptine. 
days of age which represented Day 0,3 , and 6 after the last intubation of $\mathrm{CB}$, respectively. Group 1 (control) was sacrificed at 51, 54, or 57 days of age to avoid their estrous condition. Groups 5 and 6 (ovariectomized) were killed at the age of 51 days. At autopsy, the hypophysis, adrenals, ovaries, and uterus were weighed and the bilateral thoracic, abdominal, and inguinal mammary fatty tissues were removed. These organs were examined histologically.

2 ) Histological Estimation for Mammary Gland Differentiation

The above-mentioned mammary glands which were attached to the overlying skin were streched, pinned onto cork boards, and fixed in the following fixatives. Left glands were fixed in $10 \%$ formalin and processed for wholemount preparations ${ }^{4)}$. Right glands were fixed in Bouin's fluid for 20-24 hr and processed for histological observations. After fixation, the mammary fatty tissues were dissected from the skin and each of the whole mammary glands was laid flat, dehydrated by passage through a graded series of ethnol to xylene, and embedded in a block of paraffin. The blocks were sectioned semiserially at the thickest part of the gland. Besides $\mathrm{H}-\mathrm{E}$ and the below-mentioned immunohistochemical stains, $4 \mu \mathrm{m}$ deparaffinized sections were stained with Victoria blue to distinguish the ducts from other peripheral structures ${ }^{5)}$. The ducts were coated by Victoria blue-positive elastic fibers. TEB were composed of 3-6 layers of medium-sized epithelial cells and club shaped. Lateral buds were observed along the growing duct and showed a similar club-shaped structure. In these observations, the club-shaped buds, including TEB and the lateral buds, were classified as TEB. TD progressed from TEB and had a narrow or wide lumen lined by a single layer of small cuboidal epithelial cells. $\mathrm{AB}$ arising from the bud structures appeared as clusters of 3-5 tubules with a centrally located lumen surrounded by a layer of cuboidal epithelial cells. Lobules originating from the confluence of $\mathrm{AB}$ appeared as clusters of alveoli of small diameter which had a small but patent lumen lined by a single layer of low cuboidal cells ${ }^{6,7)}$. Quantitative determinations for the mammary gland differentiation were carried out by projecting the image of the largest part of each mammary gland. The 1st, 5th, and 6th mammary glands were markedly smaller than the 2nd, 3rd, and 4th mammary glands but they did not differ significantly in sequential growth and differentiation. Therefore, the larger, flatter, and more precisely sampled 4 th mammary glands were selected to determine the development and BrdU-labeling index. In micrographs of the right 4 th mammary fatty tissues enlarged to $\times 10$, the mammary parenchyma was differentiated from the stroma. Furthermore, the parenchymal tissues were classified into each compornents according to the criteria described by Russo et $\mathrm{al}^{6}{ }^{67}$. The boundaries of the mammary tissue and of each structural unit of mammary parenchyma was outlined and the total area was measured by the use of a Digitizer (Logitec Corp., Japan). The percentages of mammary parencymal tissue per whole mammary 
fatty tissue and of each structural unit per whole mammary parenchyma were calculated and all of the data was evaluated statistically. Both Lymph nodes and large blood vessels were estimated and subtracted from the whole area of mammary fatty tissue. The degree of development estimated with the technique was confirmed with the corresponding wholemouunt preparation of the left mammary glands.

3 ) Immunohistochemical Procedures

Highly purified BrdU (Sigma Chemical Co.), monoclonal mouse anti-BrdU antibody (clone B44, Becton Dickinson), goat anti-mouse IgG (Miles Scientific), and monoclonal mouse peroxidase-antiperoxidase (PAP) complex (Miles Scientific) were purchased. Deparaffinized sections, $4 \mu \mathrm{m}$ thick, were incubated in $1 \mathrm{~N} \mathrm{HCl}$ at $37^{\circ} \mathrm{C}$ for $30 \mathrm{~min}$ to expose the antigenic sites of the incorporated BrdU in nuclear DNA by converting double strands into single strands and removing histones. The sections were then placed in absolute methanol containing $0.3 \%$ $\mathrm{H}_{2} \mathrm{O}_{2}$ for 30 min to remove any endogeneous peroxidase activity. They were treated with normal goat serum for $30 \mathrm{~min}$ and then exposed sequentially to the following reagents; 1) monoclonal mouse anti-BrdU antibody (1:200 dilution) for $60 \mathrm{~min}, 2$ ) goat anti-mouse IgG (1:20 dilution) for $30 \mathrm{~min}$, 3) monoclonal mouse PAP complex (1:100 dilution) for 30 min. All dilution were made in $0.5 \mathrm{M}$ Tris buffer, $\mathrm{pH} \mathrm{7.6}$, and the sections were washed 3 times with the same buffer after every incubation. The reactive products were detected by treating with a freshly prepared and filtered solution of $0.05 \% 3-3^{\prime}$-diaminobenzidine $4 \mathrm{HCl}$ in Tris buffer, $\mathrm{pH} 7.6$, containing $0.06 \% \mathrm{H}_{2} \mathrm{O}_{2}$ for $3 \mathrm{~min}$. All procedures were carried out at room temperature except for $\mathrm{HCl}$-treatment. At the end of the last step, $\mathrm{BrdU}$-incorporating nuclei were colored brown. An average of 2,000-3,000 glandular cells per structural unit for each animal were photographed at random from the serial sections. BrdU-labeling was determined by counting the number of labeled glandular cell nuclei per total number of glandular cells that composed the TEB, TD, AB, Lob, and ducts. Myoepithelial cells were excluded from the count. The labeling index was expressed as the number of labeled nuclei per 100 grandular cells, and the data were evaluated by analysis of variance and Newman-Keul test.

\section{Results}

Both the increase in body weights and the weights of the hypophysis, adrenals, ovaries, and uterus at autopsy were not significantly different among the groups, except for a larger hypophysis in Group 5 and a smaller uterus in Groups 5 and 6. Histological observations of these organs correlated with the gross appearances. The serum PRL levels in CB-treated Groups 2, 3, 4, and 6 deviated from those of the untreated controls in Group 1, as indicated 
in Fig. 1. It was significantly low in the ovariectomized rats in Groups $5(1.5 \pm 0.56$ $\mathrm{ng} / \mathrm{ml})$ and $6(0.4 \pm 0.03 \mathrm{ng} / \mathrm{ml})$ compared with the untreated controls (33.0 \pm 4.03 $\mathrm{ng} / \mathrm{ml})$.

As indicated in Table 2, there was a significant difference in the experimental groups in the percent area of the mammary gland parenchyma and of each structural component except for the ducts. In untreated virgin rats, aged 7-8 weeks, the peripheral structures of mammary parenchyma progressed to $\mathrm{AB}(31 \%)$ with quite few Lob $(2 \%)$ and remained TEB (4\%) and TD $(16 \%)$. In ovariectomized rat, less $\mathrm{AB}(11 \%)$ and more $\mathrm{TD}(33 \%)$ were observed in hypoplastic mammary parenchyma in which Lob was never detected.

These changes seemed to be enhanced by $\mathrm{CB}$ in the ovariectomized group. Subchronic treatment with $\mathrm{CB}$ introduced fewer $\mathrm{AB}$ (15\%) and more TD (35\%) in normally proliferating mammary parencyma. Specifically it retarded the differentiation of mammary parenchyma as observed in Group 2. In Groups 3 and 4 , the peripheral proliferation of mammary tissues was

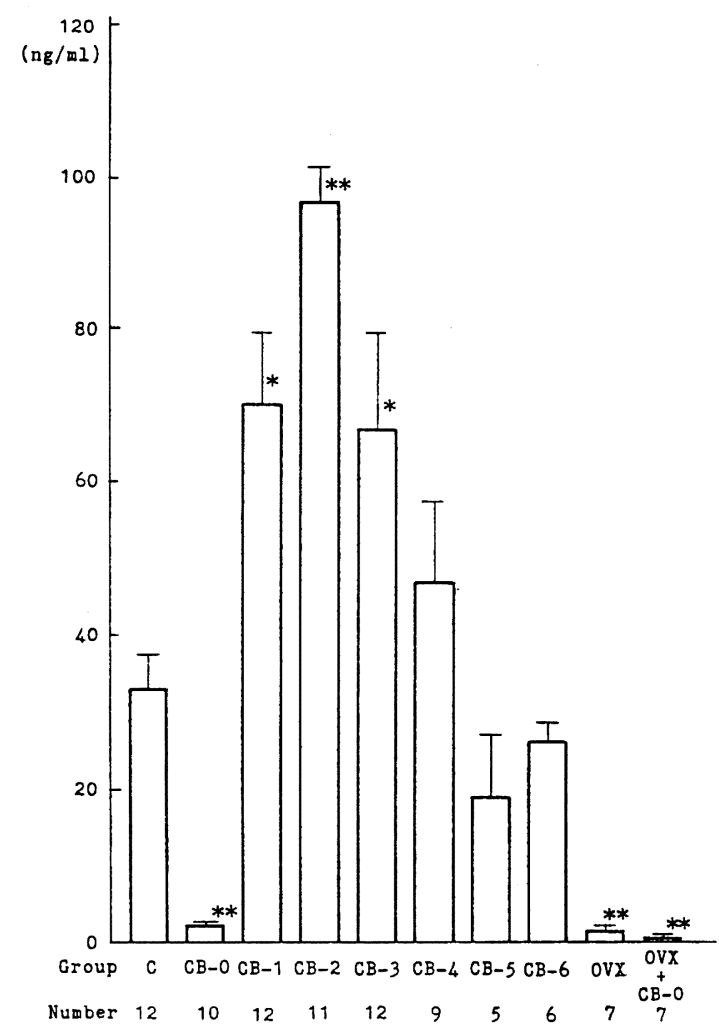

Fig. 1 Serum Prolactin Levels in Experimental Groups

$\mathrm{C}:$ Untreated control, $\mathrm{CB}-0$ : Day 0 after $\mathrm{CB}$, CB-1 : Day 1 after CB, CB-2: Day 2 after CB, CB-3 : Day 3 after CB, CB-4 : Day 4 after CB, CB-5 : Day 5 after CB, CB-6 : Day 6 after CB, OVX : Ovariectomized, OVX $+\mathrm{CB}-0$ : Day 0 after CB-treated ovariectomized. All data are stated as the Mean \pm S.E. and they show a statistically significant difference from untreated control group $\left({ }^{*} \mathrm{p}<5 \%,{ }^{* *} \mathrm{p}<1 \%\right)$. apparent corresponding to these wholemount preparations. The percentage of TEB and TD decreased significantly and the mammary parenchyma progressed more to $A B$ and Lob in significantly proliferating mammary glands. In particular, the percentage of Lob (6\%) was 5 times greater than the untreated controls and was 20 times greater than CB-treated rats. No significant difference was noted in either withdrawn group. Thus, hyperplasia and differentiation of the mammary gland parenchyma was rapidly accelerated by a rebound elevation in serum PRL levels in the rats whose development had been retarded with subchronic treatment. 
Table 2 Effect of Bromocriptine and/or Ovariectomy on Morphological Development of Mammary Gland of Pubescent Virgin Rats

\begin{tabular}{ccccccc}
\hline \multirow{2}{*}{ Group } & $\begin{array}{l}\text { Percent area } \\
\text { of parenchym }\end{array}$ & \multicolumn{5}{c}{ Percent area of structural units ${ }^{2}$} \\
\cline { 3 - 7 } & & Duct & TEB & TD & AB & Lob \\
\hline 1 & $6.74 \pm 1.04$ & $48.31 \pm 3.18$ & $3.57 \pm 2.34$ & $15.50 \pm 6.09$ & $30.74 \pm 6.04$ & $1.88 \pm 1.87$ \\
2 & $7.54 \pm 1.28$ & $45.83 \pm 0.99$ & $3.08 \pm 1.32$ & $35.38 \pm 1.71^{* *}$ & $15.48 \pm 2.28^{* *}$ & $0.32 \pm 0.42$ \\
3 & $9.74 \pm 1.42^{* *}$ & $51.19 \pm 4.34$ & $1.26 \pm 1.36$ & $6.84 \pm 3.26^{*}$ & $34.31 \pm 1.50$ & $6.41 \pm 5.33^{* *}$ \\
4 & $9.14 \pm 1.25^{* *}$ & $48.12 \pm 1.51$ & $1.08 \pm 1.40$ & $7.21 \pm 3.31^{* *}$ & $37.58 \pm 5.68^{*}$ & $6.02 \pm 3.23^{* *}$ \\
5 & $4.35 \pm 0.54^{* *}$ & $51.71 \pm 3.37$ & $3.84 \pm 2.00$ & $33.18 \pm 4.13^{* *}$ & $11.28 \pm 3.61^{* *}$ & N. P. \\
6 & $4.01 \pm 0.34^{* *}$ & $47.83 \pm 3.13$ & $12.14 \pm 6.66^{* *}$ & $31.28 \pm 7.20^{* *}$ & $8.75 \pm 4.76^{* *}$ & N. P. \\
\hline
\end{tabular}

All data are stated as the Mean \pm S. D. and they show a statistically significant difference from Group 1 which was the untreated control group $\left({ }^{*} \mathrm{p}<5 \%\right.$ and $\left.{ }^{* *} \mathrm{p}<1 \%\right)$.

1) Area of parenchymal tissue (\%) per whole area of mammary fatty tissue

2) Area of structural unit $(\%)$ per whole area of parenchymal tissue of the mammary gland TEB ; Terminal end bud, TD ; Terminal duct, AB ; Alveolar bud, Lob ; Lobule, N. P. ; not present

BrdU incorporation into the nuclear DNA could be distinctly detected by the immunohistochemical method, and myoepithelial cells which were occasionally labeled by BrdU were excluded from the count. In all of the examined groups, BrdU-labeling indexes were reduced depending on the differentiation of the mammary parenchyma from TEB to Lob and the lowest index was noted in the Lob in each group as indicated in Table 3. The indexes noted were 2, 15, 4,2 , and $1 \%$ in ducts, $\mathrm{TEB}, \mathrm{TD}, \mathrm{AB}$, and Lob of the untreated controls, respectively. Ovariectomy significantly reduced the index in each structural component except for ducts. Subchronic treatment with $\mathrm{CB}$ in virgin rats reduced the indexes also, particularly in TEB and TD. The reduction was slightly less than that in ovariectomized rats and no synergetic effect could be detected in Group 6. Compared with the untreated or CB-treated group, the indexes were significantly high in the ducts, $T D$, and $A B$ at 3 days after the termination of treatment with $\mathrm{CB}$. But, they did not exhibit high values at 6 days after termination when

Table 3 Effect of Bromocriptine and/or Ovariectomy on BrdU-labeling Index of Glandular Cells in Mammary Gland Parencymal Cells

\begin{tabular}{clclll}
\hline Group & Duct & Terminal end bud & Terminal duct & Alveolar bud & Lobule \\
\hline 1 & $2.33 \pm 1.26$ & $14.80 \pm 3.99$ & $4.45 \pm 0.68$ & $2.22 \pm 0.39$ & $1.18 \pm 0.74$ \\
2 & $1.24 \pm 0.54$ & $8.91 \pm 1.66^{* *}$ & $1.53 \pm 0.21^{*}$ & $0.85 \pm 0.16^{*}$ & $0.34 \pm 0.25$ \\
3 & $4.50 \pm 2.01^{* *}$ & $15.90 \pm 2.02$ & $5.92 \pm 1.58^{*}$ & $3.95 \pm 0.16^{* *}$ & $2.03 \pm 1.34$ \\
4 & $2.86 \pm 0.57$ & $11.54 \pm 1.12^{*}$ & $4.51 \pm 1.61$ & $2.72 \pm 1.47$ & $1.62 \pm 1.09$ \\
5 & $0.87 \pm 0.27$ & $7.36 \pm 1.79^{* *}$ & $1.29 \pm 0.25^{* *}$ & $0.76 \pm 0.26^{*}$ & N.P. \\
6 & $0.92 \pm 0.40$ & $6.78 \pm 0.80^{* *}$ & $1.00 \pm 0.32^{* *}$ & $0.59 \pm 0.24^{* *}$ & N.P. \\
\hline
\end{tabular}

All data are stated as the Mean $\pm S . D$. and they show a statistically significant difference from Group 1 which was the untreated control group $\left({ }^{*} \mathrm{p}<5 \%\right.$ and $\left.{ }^{* *} \mathrm{p}<1 \%\right)$.

BrdU-labeling index is defined as BrdU-labeled glandular cells (\%) per glandular cells in each structural unit of the mammary gland parenchyma. 
the index in TEB was rather low. A rebound increase in serum PRL levels introduced active cell kinetics in the ducts and $\mathrm{AB}$, but the activation was transitory.

\section{Discussion}

Suppression of PRL secretion with CB, which did not interfere with other endocrine processes, occurred in adult female rats at nontoxic but effective dose levels ${ }^{8)}$. It was described in this

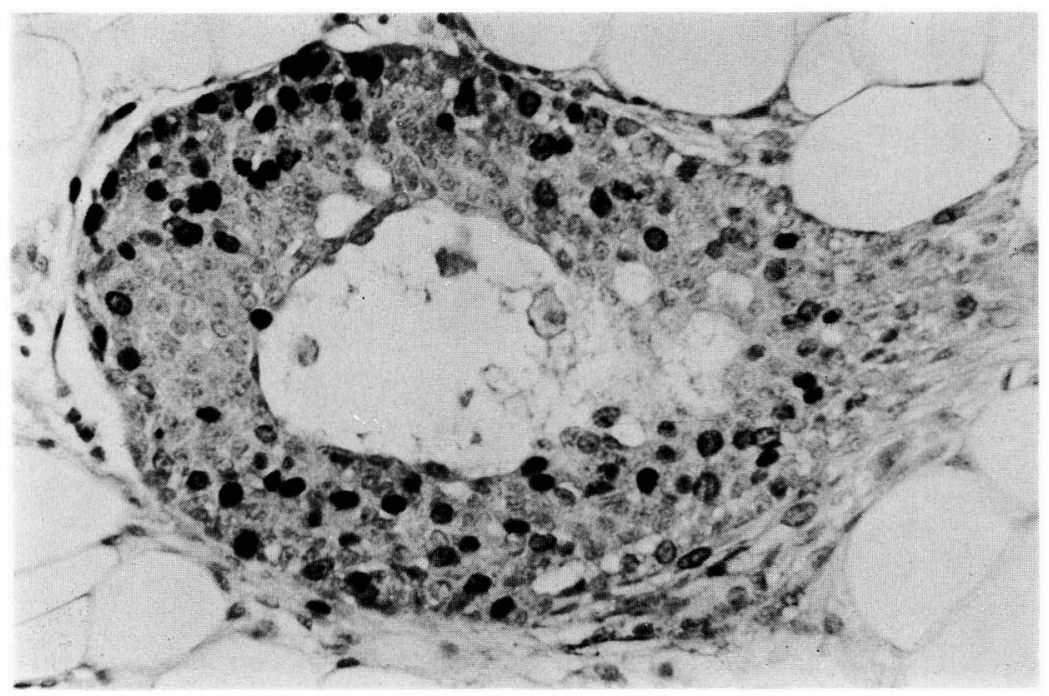

Fig. 2 a

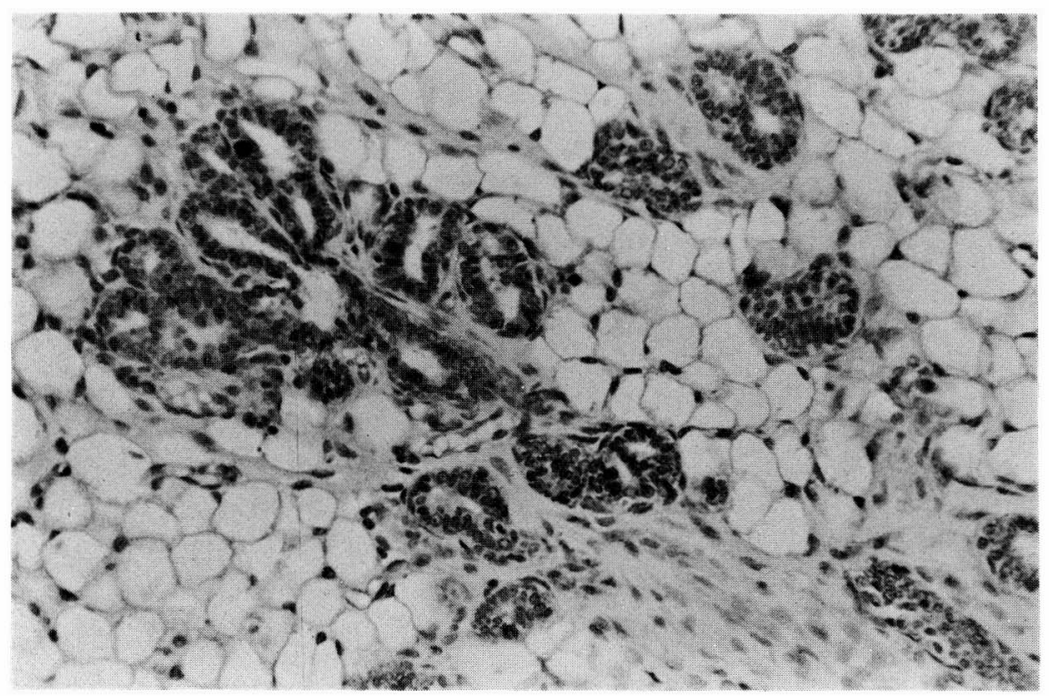

Fig. 2 b

Fig. 2 Mammary structural units of untreated contrcl rats, $\times 200$

a. TEB ; Many BrdU-labeled glandular cells can be seen.

b. Lob ; The glandular cells are occasionally labeled with BrdU. 
paper that a rebound increase in serum PRL levels occured within 3 days after the cassation of a 3 week treatment with CB. Serum PRL levels were extremely low at the termination of treatment and were noticeably high 2 days after termination. The levels were higher 1-3 days after termination than those of the untreated controls and not significantly different 4-6 days after termination from those of the untreated. This rebound phemonenon was accompanied

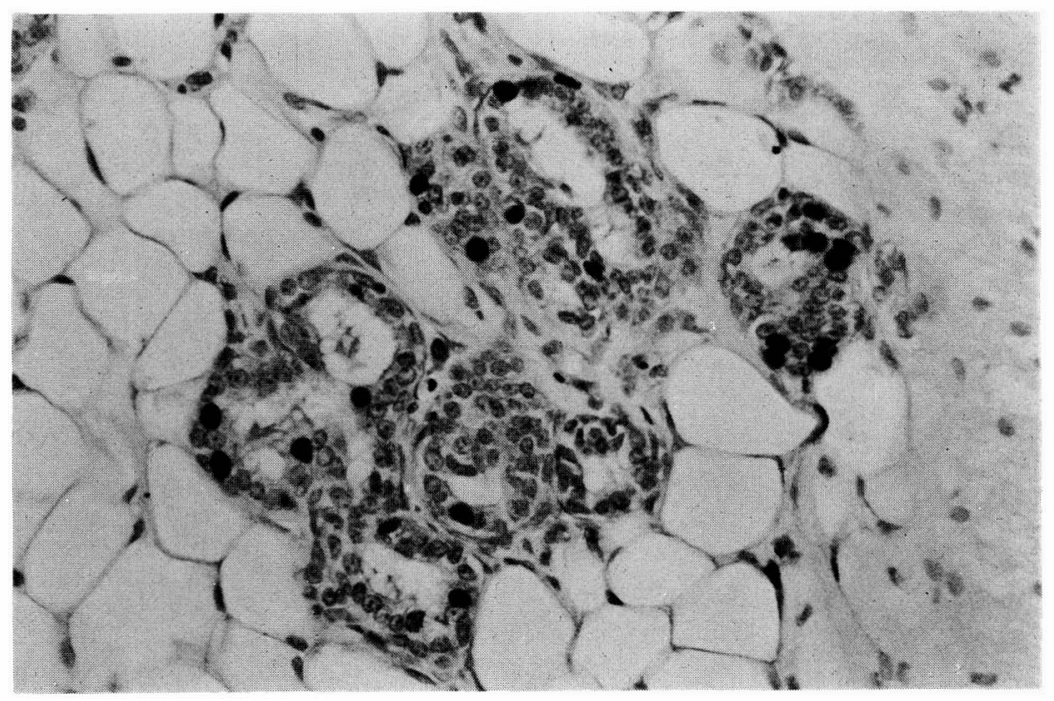

Fig. 3 a

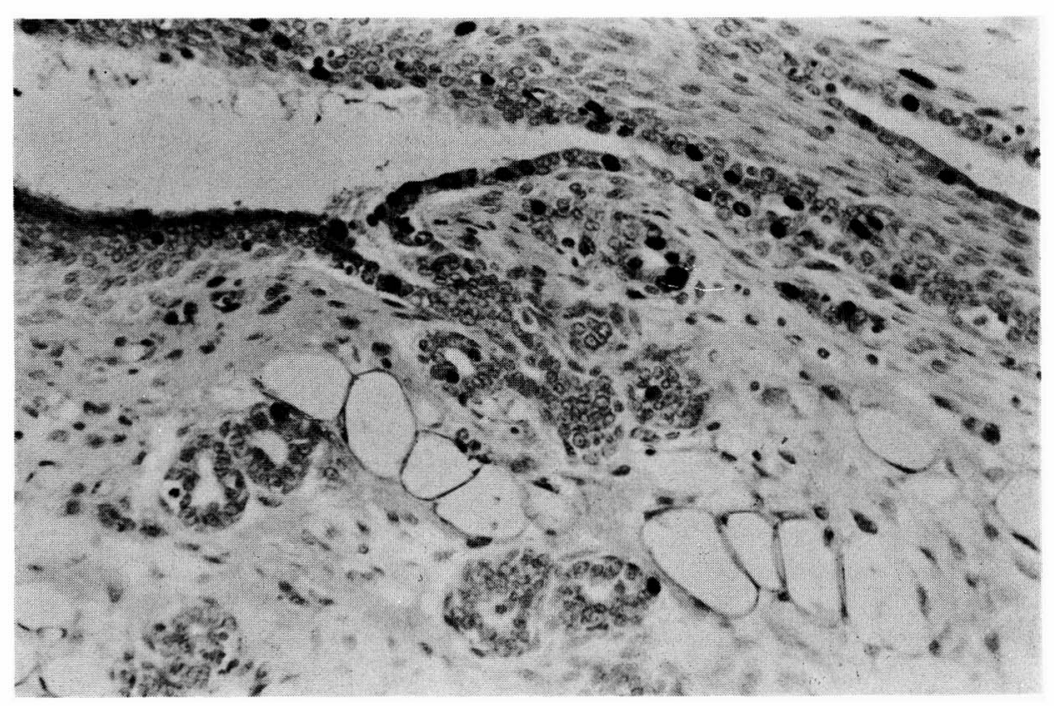

Fig. 3 b

Fig. 3 Mammary structural units of rat in Day 3 after termination, $\times 200$

a. $\mathrm{AB}$

b. ducts and $\mathrm{AB}$;

The labelig index is higher than the untreated controls. 
by marked changes in the ultrastructural characteristics of pituitary PRL cells of meta- and di-estrus pubescent virgin rats ${ }^{9)}$. An excessive accumulation of PRL-condensed mature secretory granules was found in PRL cells, where neither necrosis nor PRL degradation could be detected at the termination of subchronic treatment with CB. More extrusion of secretory granules was exhibited in PRL cells 2 days after termination. Therefore, CB acts at PRL cell levels directly to suppress PRL secretion in normally sex-cycling virgin rats, and the withdrawn of $\mathrm{CB}$ evokes a transitory elevation of serum PRL levels.

Mammary gland development from birth to adulthood has been described in rats by several authors. Some authors evaluated the peripheral differentiation according to original mammary development scores in paraffin sections ${ }^{10)}$ or wholemount preparations ${ }^{11}{ }^{12)}$. Other authors expressed it by counting the density of TEB, TD, AB, and Lob per unit area in Iwholemount preparations ${ }^{6,7,13,14)}$. In particular, the study of Russo and Russo ${ }^{6)}$ clearly expressed the histological criteria for each structural unit of mammary parenchyma. Our results which were obtained according to the criteria of them were consistent with previous reports on the postnatal development of the rat mammary gland $\left.{ }^{6},{ }^{7}\right)$ although the morphometrical methods used were slightly different. To investigate the cell kinetics with BrdU-labeling index of distinctly classified structural units of the mammary parenchyma, paraffin sections of the largest part of the 4th mammary gland were studied. In Groups 2, 5, and 6, there was a higher proportion of undifferentiated structures. Mammary differentiation was significantly suppressed in these groups and the suppression was particularly prominent in Group 6 which showed a predominance of TEB. Ovariectomy caused severe hypoplasia of the mammary gland, but our

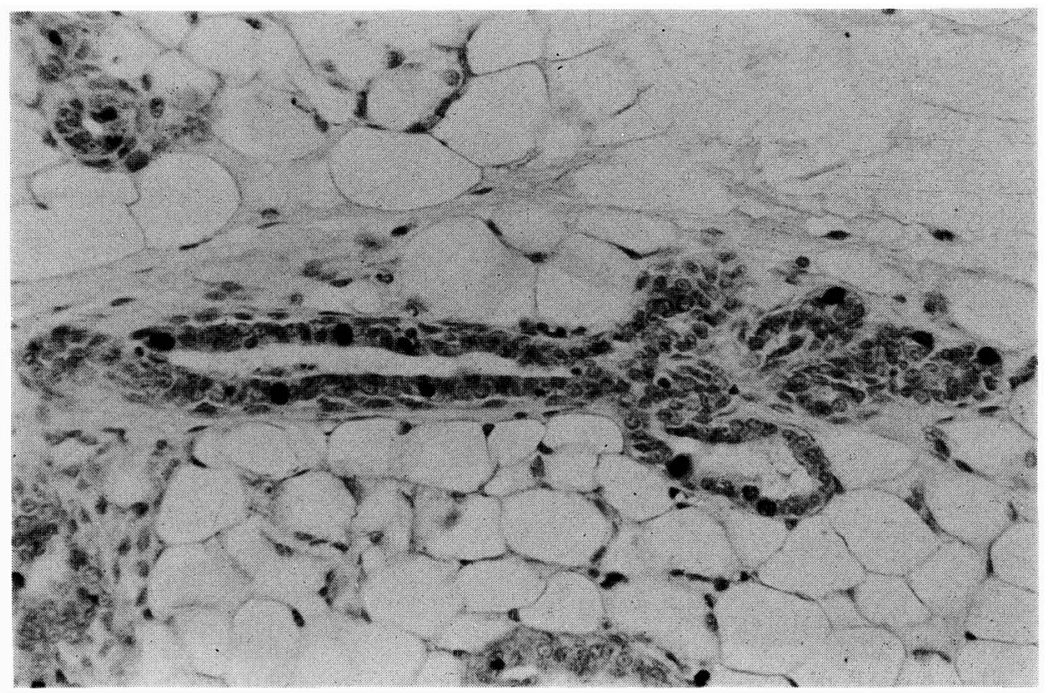

Fig. $4 \mathrm{AB}$ and ducts of rat in Day 6 after termination, $\times 200$ The labeling index is low compared with Fig. 3 . 
treatment with only CB did not so. Therefore, the absence of folliculoids and luteoids inhibited the proliferation of mammary tissues, and low seum PRL levels suppressed the differentiation of mammary parenchyma without severe hypoplasia of the glands. The mammogenic substances are involved in the regulation of differentiation as well as proliferation of the mammary gland. It is interesting to note whether or not PRL is involved only in differentiation of the mammary parenchymal cells. In Groups 3 and 4, which experienced a rebound increase in PRL in the presence of ovarian hormones, both the proliferation and differentiation of the mammary gland were stimulated. It must be noted that the percent area of the ducts was not different significantly among the groups in spite of the modified development of the mammary gland.

Tritiated thymidine incorporation into the nuclear DNA detected by autoradiography has been used to study the cell kinetics $\left.{ }^{6}, 15,16\right)$. BrdU, a pyrimidine analogue of thymidine has been relieved tritiated thymidine ${ }^{3,15,17)}$. To measure Brdu incorporation into the nuclear DNA of the mammary parenchymal cells, the immunohistochemical technique using monoclonal antibodies against BrdU was used in the rats which had been allowed to incorporate purified BrdU $2 \mathrm{hr}$ befor the sacrifice. This technique could more quickly determine the proportion of cells incorporating BrdU during the period of infusion, and dividing cells in the classified structural components of the mammary parenchyma are more distinct than in previously reported techniques. Russo and Russo ${ }^{16)}$ reported that the DNA labeling indexes of TEB, TD,

$\mathrm{AB}$, and Lob were $34,12,8$, and 0 , respectively, in 55-day-old virgin rats which had been administered tritiated thymidine. Their data were almost in agreement with our data although

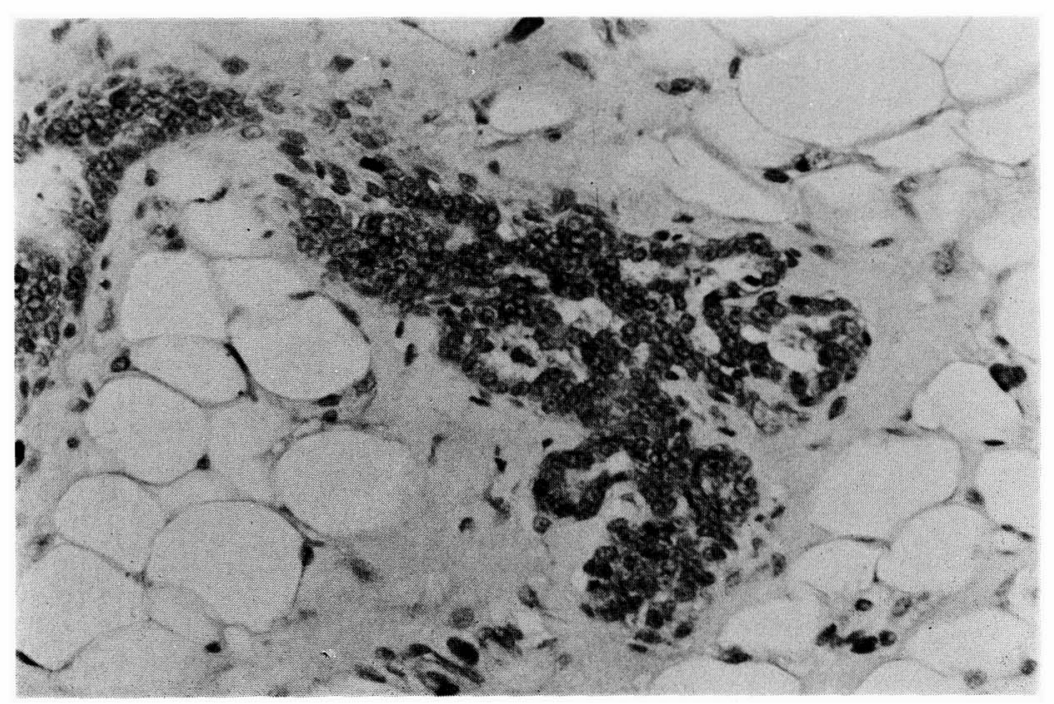

Fig. $5 \mathrm{AB}$ of ovariectomized and Bromocriptine-treated rat in Day 0 after terminaton. BrdU-labeled glandular cells are only occasionally seen in the $A B$ surrounded by thicker fibrous tissues. $\times 200$ 
our data showed relatively low indexes. This difference may be explained by a lower sensitivity of the immunohistochemical technique using the PAP method. The index was significantly high in Groups 3 which was sacrificed the day after the peak of rebound elevation in serum PRL but not in Group 4 which was sacrificed 4 days after the peak. The index was significantly low in Groups 2, 5, and 6, and there was no significant difference among them. These data indicated that the grandular cell division was diminished in these differentiationretarded groups. It may be concluded that mammary gland DNA synthesis is mostly controlled by PRL but in this animal system, both the hormonal interactions and the abnormalities of the corresponding hormone receptors within the glandular epithelial cells of the mammary gland should be investigated.

\section{Acknowledgement}

This work was in part supported by a Grant-in-Aid of Scientific Research . No. 61770259 from the Ministry of Education, Science, and Culture in Japan.

\section{References}

1) Imagawa, W., Tomooka, Y., Hamamoto, S. and Nandi, S. : Stimulation of mammary epithelial cell growth in vitro, Interaction of epidermal growth factor and mammogenic hormones. Endocrinology 116, 1514 1524, 1985.

2) Forsyth, I. A., Byatt, J.C. and Iey, S. : Hormone concentrations, mammary development and milk yield in goats given long-term Bromocriptine treatment in pregnancy. J. Endocrinol. 104, 77 85, 1985.

3) Morstyn, G., Hsu, S. M., Kinesella, T., Gratzner, H., Russo, A. and Mitchell, J. B. : Bromodeoxyuridine in tumors and chromosomes detected with monoclonal antibody. J. Clin. Invest. 72, 1844 1850, 1983.

4) Russo, J., Sabz, J., Isenberg, W.M. and Russo, I. H. : Pathogenesis of mammary carcinomas in rats by 7,12-dimethylbenz [a] anthracene. J. N.C.I. 59, 435 445, 1980.

5) Turuvov, V.S. : Pathology of Tumors in Laboratory Animals vol. 2 Tumors of the Mouse. WHO International Agency for Research on Cancer, Lyon, 1979.

6) Russo, J. and Russo, I.H. : DNA labeling index and structure of the rat mammary gland as determinants of its susceptibility to carcinogenesis. J. N. C. I. 61, 1451 1459, 1978.

7) Russo, I. H. ane Russo, J. : Developmental stage of the rat mammary gland as determinant of its susceptibility to 7,12-Dimethylbenz [a] anthracene. J. N.C. I. 61, 1439 1449, 1978.

8 ) Heuson, J.C., Waelbroeck, C., Legres, N., Gallez, G., Robyn, C. and L'Hermite, M. : Inhibition of DMBA induced mammary carcinogenesis in the rat by 2 - $\mathrm{Br}$ - $\alpha$-ergocriptine (CB-154), an inhibition of prolactin secretion, and by nafoxidine (U-11, 100A), an estrogen antagonist. Gynecol. Invest. 2, 130 137, 1971.

9) Toyoda, T., Hara, F., Sakaki, T., Oyaizu, N., Tsubura, A., Kato, Y. and Morii, S. : Quantitative ultrastructual changes in rat prolactin cells, Relationship to the rebound in serum prolactin levels after bromocriptine treatment. Acta histcchem. cytochem. 20, 537 545, 1987.

10) Kleinberg, D. L., Niemann, W., Flamm, E., Cooper, P., Babitsky, G. and Valensi, Q. : Primate 
mammary development. Effect of hypohysectomy, prolactin inhibition, and growth hormone administration. J. Clin. Invest. 75, 1943 1950, 1985.

11) Nagasawa, H., Yanai, R., Nakajima, Y., Namiki, H., Kikuyama, S. and Shiota, K. : Inhibitory effect of potassium thiocyanate on normal and neoplastic mammary development in female mice. Eur. J. cancer 16, 473 480, 1980.

12) Sheffield, L. G., Sinha, Y.N. and Welsch, C.W. : Cholera toxin treatment increases in vivo growth and development of the mouse mammary gland. Endoctinology 117, 1864 1869, 1985.

13) Benson, G.K. and Folly, S. J. : The effect of oxytocin on mammary gland involution in the rat. J. Endocrinol. 16, 189 201, 1957.

14) Sanz, M.C. A., Lie, J.M., Huang, H.H. and Hawrylewicz, E. J. : Effect of dietary protein on morphologic development of rat mammaly gland. J. N.C. I. 77, 477 487, 1986.

15) Hamada, S. : A double labeling technique combining ${ }^{3} \mathrm{H}$-thymidine autoradiography with BrdUrd immunocytochemistry. Acta hisochem. cytochem. 18, 267 270, 1985.

16) Russo, J. and Russo, I. H. : Influence of differentiation and cell kinetics on the susceptibility of the rat mammary gland to carcinogenesis. Cancer Res. 40, 2677 2687, 1980.

17) Dolbeare. F., Gratzner, H., Pallavicini, M. G. and Grey, J. W. : Flow cytometric measurement of total DNA content and incorporated bromodeoxyuridine. Proc. Natl. Acad. Sci. USA 80, 5573 5577, 1983. 